\title{
Quantitative Analysis Method of the Tea Saponin
}

\author{
Menghao Du*, Shaohai Guo, Jinping Zhang, Lisong Hu, Mingze Li \\ Research Institute of Subtropical Forestry, CAF, Fuyang, China \\ Email : ${ }^{*} 13868188403 @ 139 . c o m$
}

How to cite this paper: $\mathrm{Du}, \mathrm{M}$. H., Guo, S. H., Zhang, J. P., Hu, L. S., \& Li, M. Z. (2018). Quantitative Analysis Method of the Tea Saponin. Open Journal of Forestry, 8 , 61-67.

https://doi.org/10.4236/ojf.2018.81005

Received: December 4, 2017

Accepted: January 6, 2018

Published: January 9, 2018

Copyright (c) 2018 by authors and Scientific Research Publishing Inc. This work is licensed under the Creative Commons Attribution International License (CC BY 4.0).

http://creativecommons.org/licenses/by/4.0/

\begin{abstract}
In this study, the detection method of tea saponin has been studied firstly. Determining the maximum absorption wavelength is $540 \mathrm{~nm}$. Standard curve equation is $\mathrm{y}=0.0015 \mathrm{x}-0.0885$. The correlation coefficient $\mathrm{r}=0.9983(p<$ 0.01 ). The relative standard deviation is $1.13 \%$. Reclaimable rate of adding standard sample is $89.5 \%-97.7 \%$. Comparing vanille-sulfuric acid of gravimetric determination, the maximum deviation is $3.27 \%$, indicating that vanille-sulfuric acid method is worth of quantitative analysis of tea saponin.
\end{abstract}

\section{Keywords}

Vanillin-Sulfuric Acid Color Reaction, Saponin, Absorption Spectrum

\section{Introduction}

Saponins are a class of chemical compounds found in particular abundance in various plant species. More specifically, they are amphipathic glycosides grouped phenomenologically by the soap-like foaming they produced when shaken in aqueous solutions, and structurally by having one or more hydrophilic glycoside moieties combined with a lipophilic triterpene derivative. Tea saponin (extracted from tea seeds), a natural Non-ionic surfactant, not only has a good emulsifying, separating and dispersing capability but is also a good foaming and foam stabilizer with a great and cleaning capacity with a hydrophile-lipophilic balance value of 16 (Wu \& Raven, 1998). Thus it can be used as foam stabilizer for the building concrete (Zhang et al. 1993), pesticide synergist (Lin, 1977), soil amendment (Hong et al. 2000), antioxidants (Ibrahim et al, 2006), Pesticides and surfactants (Kuo et al. 2005), so it is widely used in daily chemical industries, building materials, food industries and agriculture. Usually quantitative analyses of saponins are used by gravimetric method (General Administration of Quality Supervision, 
2006). But gravimetric method detected saponins would spend more time as the complexity steps. So we explore a new colorimetric method for quantitative analysis of saponins. There are a lot of colorants that are used in colorimetric methods (Guo et al. 2011). In this paper, vanillin-sulfuric acid was selected as colorants. The principle of coloration is that saponins are dehydrogenated under the action of sulfuric acid, and then oxidized with vanillin to produce colored matter.

\section{Material and Methods}

\subsection{Main Materials}

The main materials used in this study were described in Table 1.

\subsection{Main Equipments}

The main instruments used in this study were described in Table 2.

\subsection{The Preparation of Standard Solution (Omer et al., 2015)}

Dissolve about $0.2500 \mathrm{~g}$ of tea saponin standard with $300 \mathrm{ml} 85 \%$ ethyl alcohol in $500 \mathrm{~mL}$ dark glass volumetric flask and add alcohol up to volume, special solution $0.50 \mathrm{mg} / \mathrm{ml}$.

\subsection{Colour Reaction and Determination of Maximum Absorption Wavelength (Gu et al. 2000; Chen et al., 2012)}

Add $1 \mathrm{ml}$ of tea saponin standard solution with $1 \mathrm{ml}$ of $8 \%$ vanillin (w/v) into 10 $\mathrm{ml}$ sample tube with a stopper, then put in ice-water bath, and then $8 \mathrm{ml}$ of $77 \%$ sulfuric acid (v/v) was added. After shaking up, the tube was capped and placed in Oven at $60^{\circ} \mathrm{C}$ for $30 \mathrm{~min}$. Cool down the solution in ice-water bath for $10 \mathrm{~min}$ and reach solution to room temperature before UV analysis. Detecting the absorbance of the solution was used $1 \mathrm{~cm}$ quartz colorimetric utensil and ultraviolet-visible spectrophotometer full-band scanning. The blank solution 1:8

Table 1. Reagents.

\begin{tabular}{ccc}
\hline & Grade & Manufacturer \\
Tea saponin standard & $99 \%$ & Preparation by our lab \\
Crude tea saponin & $\geq 50 \%$ & Preparation by our lab \\
Ethyl alcohol & Analytical pure & Guoyao chemical reagent Co. LTD \\
Methanol & Analytical pure & Guoyao chemical reagent Co. LTD \\
Sulfuric acid & Analytical pure & Guoyao chemical reagent Co. LTD \\
Hydrochloric acid & Analytical pure & Guoyao chemical reagent Co. LTD \\
Sodium hydroxide & Analytical pure & Guoyao chemical reagent Co. LTD \\
Acetone & Analytical pure & Guoyao chemical reagent Co. LTD
\end{tabular}


Table 2. Equipments.

\begin{tabular}{|c|c|c|}
\hline & Type & Manufacturer \\
\hline $\begin{array}{l}\text { Ultraviolet-visible } \\
\text { spectrophotometer }\end{array}$ & UV-2550 & Shimadzu corporation \\
\hline Centrifuge & Avanti J-E & Beckman \\
\hline Electronic balance & S-114 & Sartorius \\
\hline Vortex mixer & XW-80A & $\begin{array}{l}\text { Haimen qilinbeier instrument } \\
\text { manufacturing Co. LTD }\end{array}$ \\
\hline Electro-thermostatic blast oven & DGG-9140 & $\begin{array}{l}\text { Shanghai senxin experimental } \\
\text { instrument Co. LTD }\end{array}$ \\
\hline Thermostat water bath & XMTE-8112 & $\begin{array}{c}\text { Shanghai jinghong experimental } \\
\text { equipment Co. LTD }\end{array}$ \\
\hline Vacuum pump & SHZ-D(III) & $\begin{array}{l}\text { Shanghai yuhua instrument } \\
\text { equipment Co. LTD }\end{array}$ \\
\hline
\end{tabular}

(volume ratio) mixtures of vanillin solution and sulfuric acid were prepared as above.

\subsection{Standard Curve Determination (Zhang et al., 2009)}

Series of the standard solution $(0.1 \mathrm{ml}, 0.3 \mathrm{ml}, 0.52 \mathrm{ml}, 0.7 \mathrm{ml}$ and $0.94 \mathrm{ml})$ were taken and the mixed solutions were prepared by the method described as above for measuring absorbance values. The resulting standard curve was assessed with Shimadzu Corporation software.

\subsection{Precision Experiment (Chen, 2008)}

Add $0.9 \mathrm{ml}$ of tea saponin standard solution to each tube (five), and the each mass was recorded to $0.45 \mathrm{mg}$, then detect the absorbance of solutions using methods of 2.4 and 2.5. Through calculating standard deviation (S) and relative standard deviation (RSD) obtained the precision of this method.

\subsection{Sample Added Recovery (Zhang et al., 2009)}

Add respectively $0.1500,0.2000,0.2500,0.3000$ and $0.3500 \mathrm{mg}$ saponin standard powder into $0.4 \mathrm{ml}$ of tea saponin standard solution to each tube (five), then detect the absorbance of solutions using methods of 2.4 and 2.5 and calculate sample added recovery.

\subsection{Stability Experiment (Chen et al., 2012)}

Absorbance changes of $0.9 \mathrm{ml}$ tea saponin standard solution of within 4 hour were detected using methods of 2.4 and 2.5 .

\subsection{Gravimetric Determination}

Refer to SNT 1852-2006 Determination of saponin content in tea saponin for export. 


\subsection{Data Processing Method}

The resulting standard curve was assessed with Microsoft excel. The evaluation of statistical significance was determined by the one-way ANOVA test, these analyses were done with SPSS for WINDOWS, version 19.0.

\section{Results and Discussion}

\subsection{Absorption Spectrogram of Tea Saponin}

Tea saponin is maximum absorption at the wave length about $540 \mathrm{~nm}$ (Figure 1), so we used the characteristic curve for the determination tea saponin.

\subsection{Standard Curve Determination}

According to the absorbance of the standard tea saponin solution and the standard curve (Figure 2) with vanillin sulfuric acid colorimetric method, which is obtained at the maximum absorption wavelength of $540 \mathrm{~nm}$ at different concentration of tea saponin, the regression equation is as follows: $y=0.0015 x-0.0885$, $\mathrm{R}^{2}=0.9983(p<0.01)$. The tea saponin concentration is positively correlated with the absorbance value; it means this equation can be used as the quantitative determination of tea saponin concentration.

\subsection{Precision Experiment}

Precision drawing concentration of $0.5 \mathrm{mg} / \mathrm{ml}$ reference substance solution, 0.9 $\mathrm{ml}$, sample 5 consecutive times, the measured values of tea saponin, $\mathrm{S}=0.00507$, RSD $=1.13 \%$ (Table 3 ).

\subsection{Recoveries Experiment}

The recovery rate of the sample after the labeling was between $89.5 \%$ and $97.7 \%$ (Table 4). It is indicated that the veracity of the vanille-sulfuric acid method can meet the general analysis requirements.

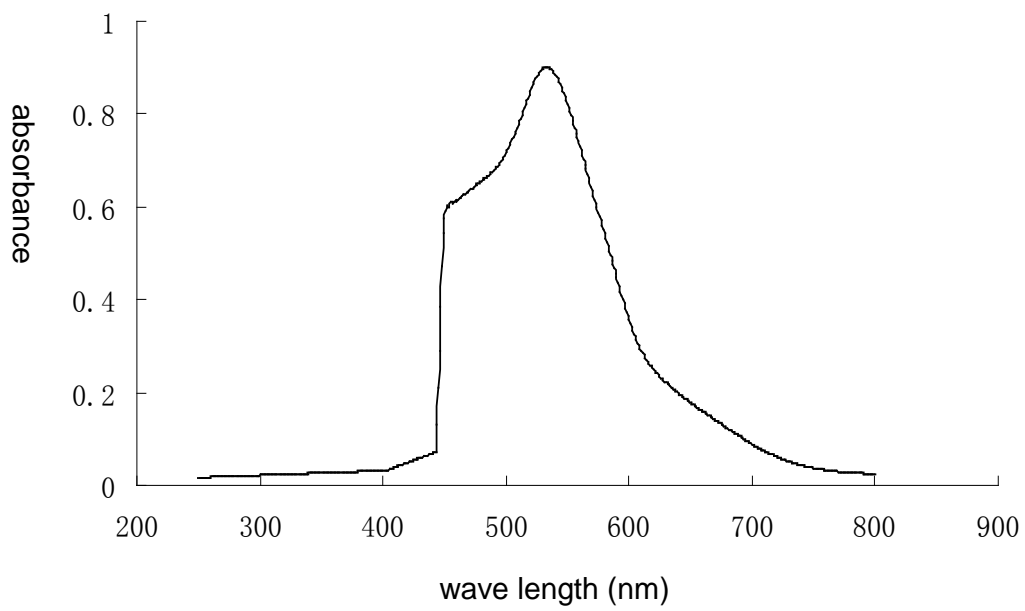

Figure 1. The absorption spectrum of tea saponin. 


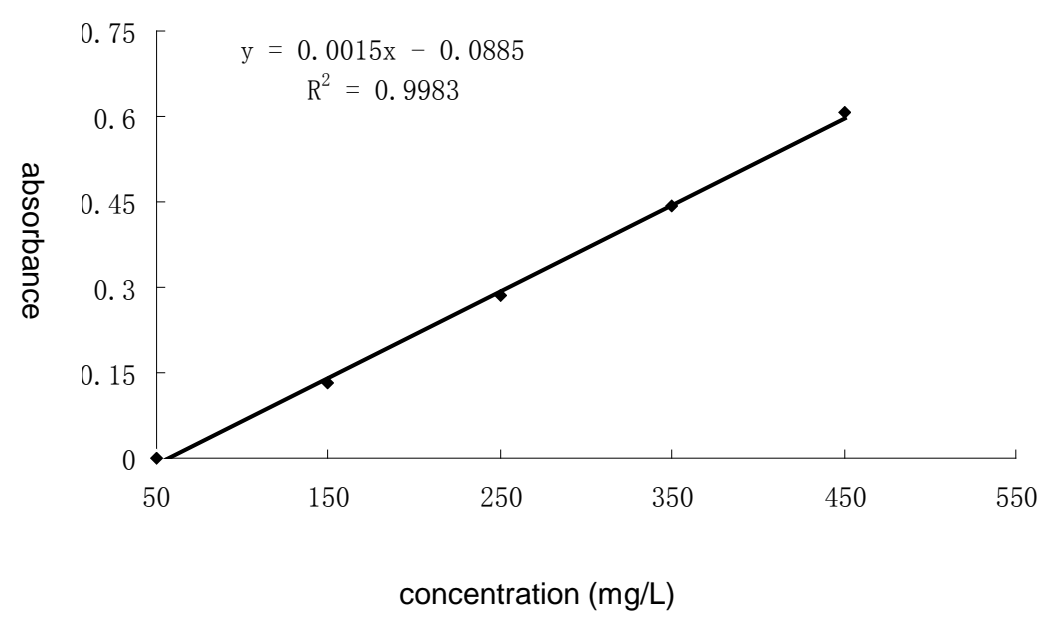

Figure 2. The standard curve of tea saponin.

Table 3. The results of precision experiment.

\begin{tabular}{ccccc}
\hline No. & Weight of tea saponin $/ \mathrm{mg}$ & Determination weight of tea saponin $/ \mathrm{mg}$ & $\mathrm{S} / \mathrm{mg}$ & $\mathrm{RSD} / \%$ \\
\hline 1 & 0.450 & 0.432 & 0.00507 & 1.13 \\
2 & 0.450 & 0.424 & & \\
3 & 0.450 & 0.431 & & \\
4 & 0.450 & 0.438 & & \\
5 & 0.450 & 0.429 & & \\
\hline
\end{tabular}

Table 4. The results of recoveries experiment.

\begin{tabular}{ccccc}
\hline No. & $\begin{array}{c}\text { Weight of tea } \\
\text { saponin in first/mg }\end{array}$ & Additive amount/mg & $\begin{array}{c}\text { Determination weight } \\
\text { of tea saponin } / \mathrm{mg}\end{array}$ & Recovery rate/\% \\
\hline 1 & 0.200 & 0.153 & 0.338 & 90.2 \\
2 & 0.200 & 0.205 & 0.397 & 96.1 \\
3 & 0.200 & 0.252 & 0.441 & 95.6 \\
4 & 0.200 & 0.294 & 0.463 & 89.5 \\
5 & 0.200 & 0.345 & 0.537 & 97.7 \\
\hline
\end{tabular}

\subsection{Stability Experiment}

The storage time is positively correlated with the absorbance value (Figure 3 ), the regression equation is as follows: $y=0.0003 x-0.782, \mathrm{R}^{2}=0.9983(p<0.01)$. Precision drawing the first absorbance 0.7891 for the sample solution, each interval of sometime detected, a continuous inspection $4 \mathrm{~h}$, the results of tea saponin absorbance RSD values of $1.62 \%$ (50 min) and 7.6\% (4 h), indicating that the basic stability within $1 \mathrm{~h}$.

\subsection{Comparison of Two Detection Methods}

Exactly the same conditions and samples, comparing vanille-sulfuric acid of gravimetric determination, the maximum deviation is $3.27 \%$ (Table 5), indicating 


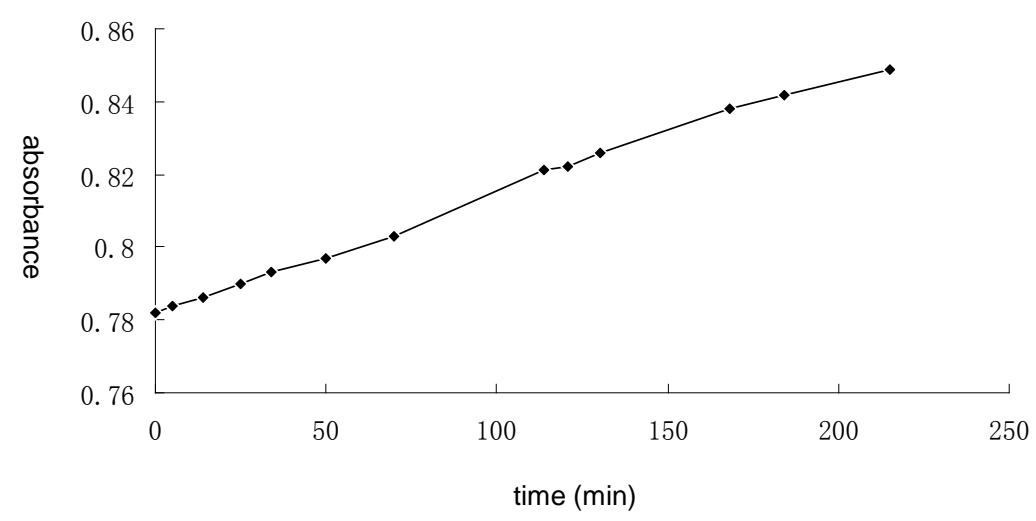

Figure 3. The result of stability test.

Table 5. The comparison of two detection methods.

\begin{tabular}{ccccc}
\hline \multirow{2}{*}{ Method } & \multicolumn{4}{c}{ Weight of saponin/\% } \\
\cline { 2 - 5 } & 1 & 2 & 3 & mean value \\
\hline Gravimetric determination & 56.97 & 57.12 & 56.63 & $56.91 \pm 0.25$ \\
Vanille-sulfuric acid & 59.05 & 58.59 & 59.31 & $58.98 \pm 0.36$ \\
\hline
\end{tabular}

that vanille-sulfuric acid method is worth of quantitative analysis of tea saponin.

\section{Conclusion}

Quantitative analysis method of the tea saponin vanillin-sulfuric acid color reaction has been analyzed. Determining the maximum absorption wavelength is 540 $\mathrm{nm}$. Standard curve equation is $\mathrm{y}=0.0015 \mathrm{x}-0.0885$. The correlation coefficient $\mathrm{r}=0.9991$. The relative standard deviation is $1.13 \%$. Reclaimable rate of adding standard sample is $89.5 \%$ - $97.7 \%$. Comparing vanille-sulfuric acid of gravimetric determination, the maximum deviation is $3.27 \%$, indicating that vanille-sulfuric acid method is worth of quantitative analysis of tea saponin.

\section{Acknowledgements}

This work was financial supported by "the Fundamental Research Funds for the Central Non-profit Research Institution of CAF” and Zhejiang province key research and development plan (Grant No.RISF201361324, No. 2017C02003).

\section{References}

Chen, X. X. (2008). Study on the Process of Producing Sugar from Camellia Seed Meal. Doctor Thesis, Wuhan: Wuhan Polytechnic University.

Chen, Y., Liu, S. B., \& He, L. X. (2012). Quantitative Analysis of Saponins in Camellia Seed Cake and Tea Saponins. Journal of the Chinese Cereals and Oils Association, 27, 105-111.

General Administration of Quality Supervision (2006). Inspection and Quarantine of the People's Republic of China. SNT 1852-2006 Determination of Saponin Content in Tea 
Saponin for Export.

Gu, L. W., \& Gu, W. Y. (2000). Spectrophotometric Determination of Soyasaponins. Journal of the Chinese Cereals and Oils Association, 15, 38-42.

Guo, X., Xu, R. N., \& Qin, Z. R. (2011). Advances in the Research of New Non-Ionic Surfactant Tea Saponin. China Cleaning Industry, No. 2, 43-46.

Hong, K. J., \& Tokunaga, S. (2000). Extraction of Heavy Metals from MSW Incinerator Fly Ash Using Saponins. Chemosphere, 41, 345-352.

https://doi.org/10.1016/S0045-6535(99)00489-0

Ibrahim, M., Khan, A. A., Tiwari, S. K. et a1. (2006). Antimicrobial Activity of Sapindus mukorossi and Rheum emodi Extracts Against H. pylori: In Vitro and In Vivo Studies. World Journal of Gastroenterology, 14, 7136-7142.

https://doi.org/10.3748/wig.v12.i44.7136

Kuo, Y. H., Huang, H. C., Yang Kuo, L. M. et al. (2005). New Dammarane-Type Saponins from The galls of Sapindus mukorossi. Journal of Agricultural and Food Chemistry, 53, 4722-4727. https://doi.org/10.1021/jf047963s

Lin, Q. S. (1977). The Chemical Composition of Chinese Herbal Medicine. Beijing: People's Medical Publishing House.

Omer, H., Ahmed, A., \& Wang, C. M. (2015). Determination of Tea Saponin in Camellia Seed Oil with UV and HPLC Analysis. World Journal of Engineering and Technology, 3, 30-37. https://doi.org/10.4236/wjet.2015.34C004

Wu, Z. Y., \& Raven, P. (1998). Flora of China. Beijing: Beijing Science Press.

Zhang, M. J., Liu, P. R., Zhao, J. Z. et al. (1993). Study on the Comprehensive Utilization of Sapindus mukorssi. Natural Product Research and Development, 5, 76-78.

Zhang, S. Y., Cui, X. Y., Shao, J. et al. (2009). Optimization of Extracting Tea Saponin from the Cake of Camellia Seeds by Orthogonal Design. Journal of Southwest Univer sity for Nationalities, 35, 1028-1031. 